\title{
Asisten Navigasi untuk Orang dengan Gangguan Penglihatan Menggunakan Ultra Sonic (Sonar Vision) Untuk Yayasan Mitra Netra
}

\author{
Rudy Susanto ${ }^{1}$, Johannes ${ }^{2}$, Wiedjaja Atmadja ${ }^{3}$, Raditya Eko Prabowo ${ }^{4}$, Nicholas Julian ${ }^{5}$ \\ Universitas Bina Nusantara \\ ${ }^{1}$ rudy.susanto@binus.ac.id
}

Received: January $21^{\text {st }}, 2020 /$ Revised: February $12^{\text {th }}$ 2020/ Accepted: February $24^{\text {th }}, 2020$

\begin{abstract}
Generally, people with visual impairments in the low vision category use sticks to find ways to deal with obstacles in front of them. However, this detection can only be felt as long as the stick is used. The purpose of this community service activity is to made a sonar vision set using a sonar sensor that can be attached to the wrist and belt. This device is designed to detect obstacles up to a distance of 3 meters. This activity was carried out at the Mitra Netra Foundation. The approach used is the creation, provision and education of the use of the Sonar Vision module for people with visual impairments. The results of this activity show that 100 low vision sufferers have benefited from this system, where $84 \%$ of them feel that sonar vision helps them in navigation.
\end{abstract}

Keywords: sonar; low vision; obstacle detection

\begin{abstract}
Abstrak
Para penyandang gangguan penglihatan kategori low vision pada umumnya menggunakan tongkat untuk mencari cara menghadapi rintangan yang ada di hadapannya. Namun, deteksi ini hanya bisa dirasakan sepanjang tongkat yang digunakan. Tujuan kegiatan pegabdian ini adalah untuk membuat sebuah alat sonar vision set dengan menggunakan sensor sonar yang dapat dipasang pada pergelangan tangan dan sabuk. Alat ini dirancang untuk mendeteksi rintangan hingga jarak 3 meter. Kegiatan ini dilaksanakan pada Yayasan Mitra Netra. Pendekatan yang digunakan adalah pembuatan, pemberian dan edukasi penggunaan alat Sonar Vision kepada penyandang gangguan penglihatan. Hasil kegiatan ini menunjukkan 100 penderita penglihatan rendah telah mendapatkan manfaat dari sistem ini, di mana $84 \%$ dari mereka merasa bahwa penglihatan sonar membantu mereka dalam navigasi.
\end{abstract}

Kata Kunci: sonar; low vision; deteksi halangan

\section{Pendahuluan}

Yayasan Mitra Netra adalah organisasi nirlaba yang memusatkan programnya pada upaya meningkatkan kualitas dan partisipasi tunanetra di bidang pendidikan dan lapangan kerja. Didirikan di Jakarta tanggal 14 Mei 1991, dan berstatus sebagai badan hukum dengan terdaftar pada Tambahan Berita Negara tanggal 14/12 tahun 2001 nomor 100.

Yayasan ini didirikan oleh beberapa orang tunanetra yang berhasil menyelesaikan studinya di perguruan tinggi bersama-sama dengan sahabatsahabat mereka yang bukan tunanetra;mmereka adalah beberapa dari sangat sedikit orang yang memprihatinkan minimnya layanan dan fasilitas pendukung bagi tunanetra yang sedang menempuh pendidikan di sekolah umum dan perguruan tinggi.

Penyandang disabilitas tunanetra mengalami berbagai kendala dalam kehidupan sehari-hari mereka, karena kecacatan pada indera penglihatan mereka. Kegiatan sehari-hari seperti berjalan/bernavigasi, membaca, dan menikmati hiburan menjadi sangat sulit \& terbatas (Blindness: Challenge and Achievement, 2015), dan mereka butuh alat bantuan untuk melakukan kegiatankegiatan tersebut, contohnya seperti tongkat, 
pemandu, huruf Braille, dan media hiburan audibel. Juga bagi yang buta parsial, hidup juga tidak jauh lebih baik. Masih ada kesulitan yang dialami seperti kesulitan dengan tulisan-tulisan kecil, mengartikan simbol dan memproses warna pada banyak situs di internet, dan mereka butuh peralatan atau piranti lunak yang dapat membesarkan gambar sehingga lebih mudah dilihat. (Sandi, 2001)

Tidak hanya itu, infrastruktur untuk penderita tunanetra di Indonesia juga bisa dibilang belum memadai, bahkan di ibukota sekalipun. Trotoar yang sebagian besar masih dalam keadaan memprihatinkan dapat membahayakan penderita tunanetra. Transportasi umum juga masih belum terlihat menerapkan kebijakan atau fitur yang membantu penderita tunanetra. Meski begitu, terlihat secercah harapan bagi mereka, karena belakangan ini sedang diangkat isu untuk membantu kaum difabel dalam pemerintahan daerah, terutama pada level propinsi, dengan menjalankan pembangunan \& pembenahan infrastruktur bagi kaum difabel.

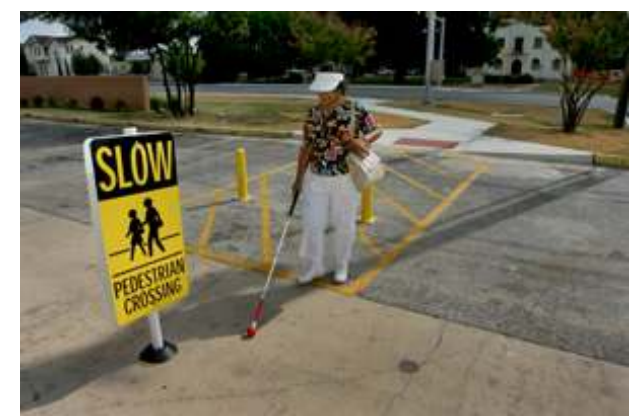

Gambar 1. Berjalan dengan tongkat. (American Foundation for the Blind, n.d.)

Namun, masih kita melihat perangkatperangkat untuk membantu penyandang tunanetra yang dapat terbilang mahal, seperti yang tertulis pada Future Reflections Winter 1986, Vol. 5 No. 1 bagian TECHNICAL DEVICES AND SPECIAL EQUIPMENT FOR THE BLIND dari The National Federation of the Blind Magazine for Parents and Teachers of Blind Children dimana ComputerDriven Braille Printer saja dibanderol dengan harga US\$3000 - 15000 (Rp. 49.000.000 195.000.000). Padahal, derita mereka sebagai penyandang tunanetra sudah cukup membebani hidup mereka, dan sebaiknya tidak dibebani lebih jauh dengan mahalnya harga perangkat yang seharusnya membantu hidup mereka.

Melihat kondisi ini, kami ingin memberikan ikut berpartisipasi dalam memberikan dukungan bagi penyandang tunanetra untuk melaksanakan aktivitas mereka, terutama dalam hal navigasi dan berjalan, yaitu dengan modul "Feedback Assist for Low Vision Users" atau kami sebut dengan SonarVision, perangkat untuk penyandang tunanetra yang berfungsi untuk mendeteksi objek di depan sensor dan memperingatkan pengguna atas seberapa dekatnya objek tersebut dengan getaran yang semakin kencang apabila objek tersebut semakin dekat dengan sensor. Dengan inovasi ini, kami dapat memulai secara nyata dalam pemberian dukungan tersebut.

Tujuan yang kami targetkan adalah membuat sebuah alat dengan teknologi terbaru untuk membantu kaum difabel. Kami yakin dengan teknologi microcontroller yang semakin anyar dan bersahabat dengan pengguna, kami dapat dengan mudah membuat sebuah alat yang dapat membantu navigasi penyandang tunanetra yang disesuaikan dengan kebutuhan pengguna penyandang tunanetra sehingga lebih maksimal dalam membantu navigasi mereka.

\section{Pelaksanaan dan Metode}

Metode pelaksanaan kegiatan ini dilakukan dengan pembuatan alat dan penyempurnaan modul yang ada.

Pertama, penyempurnaan desain modul, dengan kegiatan yang kami lakukan meliputi dari peringkasan desain casing produk hingga desain tata letak komponen. Desain alat dilakukan sebanyak 4 kali revisi sesuai dengan ergonomi dan masukan dari calon pengguna alat kami, proses desain yang dilakukan sesuai dengan Gambar $2-5$.

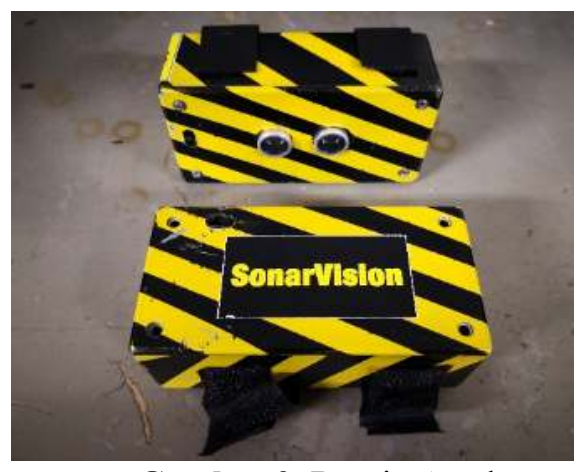

Gambar 2. Desain Awal 


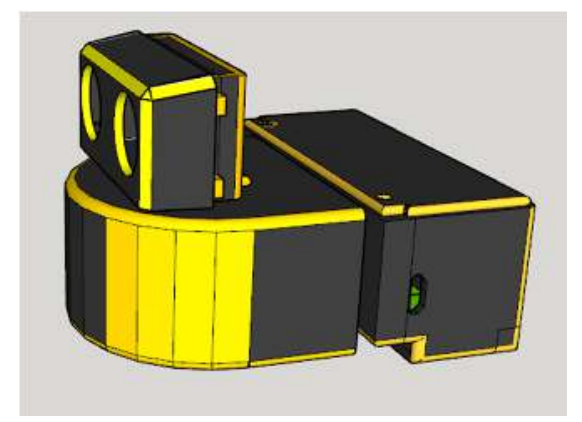

Gambar 3. Penyempurnaan tahap 1

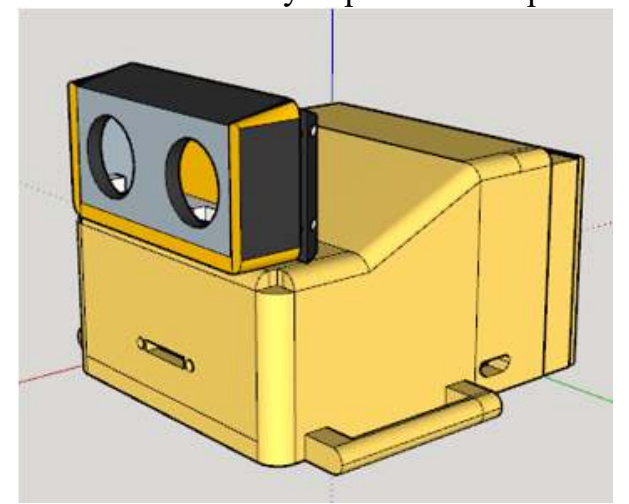

Gambar 3. Penyempurnaan tahap 2

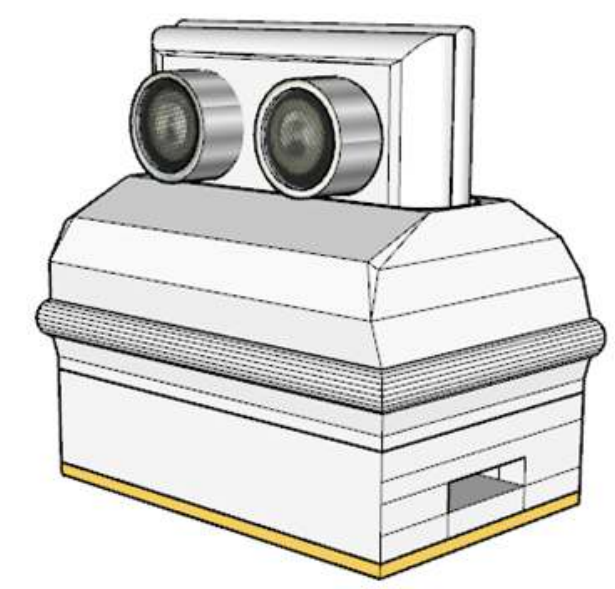

Gambar 4. Peyempurnaan tahap 3

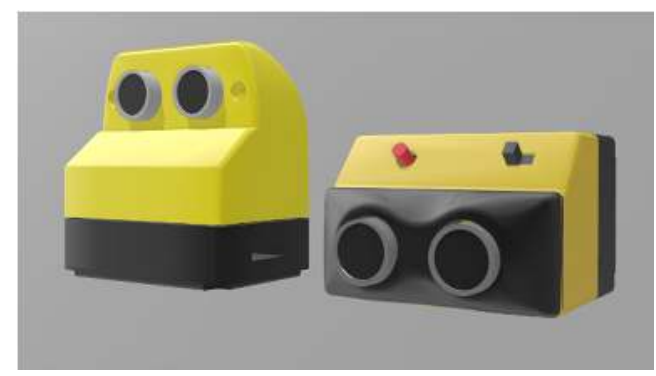

Gambar 5. Hasil akhir

Hasil akhir pada Gambar 5 adalah hasil iterasi dengan calon pengguna pada Yayasan Mitra
Netra. Dalam proses desain ini ditambahkan fitur pengisian daya secara nirkabel.

Proses produksi dalam rangka pemenuhan rencana output yakni berjumlah 200 PCs alat. Dimana 200 PCs alat tersebut terbagi menjadi 2, yakni 100 PCs konfigurasi pergelangan tangan dan 100 PCs konfigurasi pinggang. Tingkat penyelesaian produksi mencapai $100 \%$. Proses produksi bertempat di laboratorium Hardware jurusan Sistem Komputer Universitas Bina Nusantara.

\section{Hasil dan Pembahasan}

Kegiatan pengabdian ini dimulai dengan melakukan pembuatan dan pengujian alat pada Universitas Bina Nusantara. Pembuatan alat dilakukan dalam periode 3 bulan. Seperti pada gambar 6 dan 7.

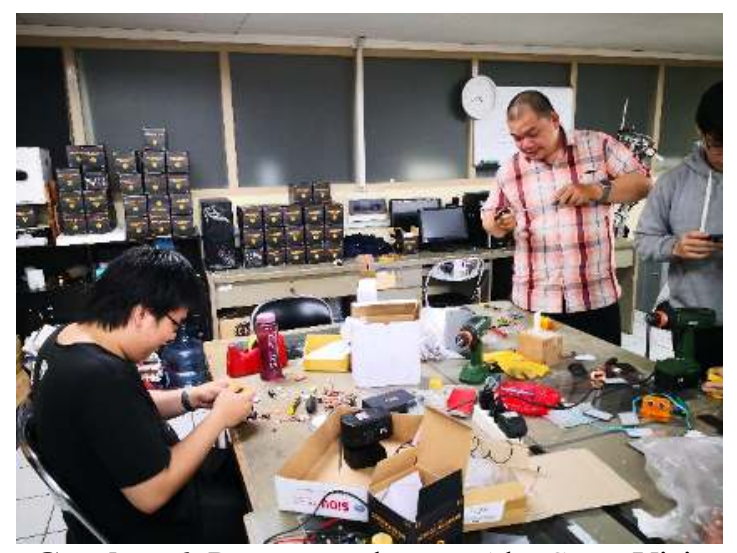

Gambar 6. Proses pembuatan Alat SonarVision

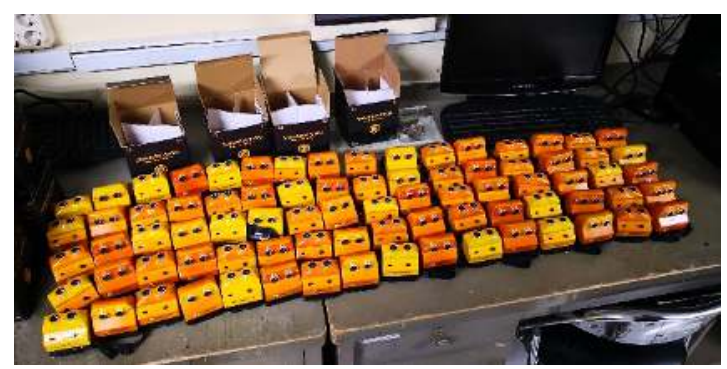

Gambar 7. Modul Sonar Vision

Setelah modul siap dan selesai tahap pengujian, alat disosialisasikan dan diberikan kepada penyandang tunanetra dan low vision pada Yayasan Mitra Netra sebanyak 100 alat, dan 100 alat didistribusikan ke mitra yayasan diluar Jakarta seperti terlihat pada gambar $8-10$ 


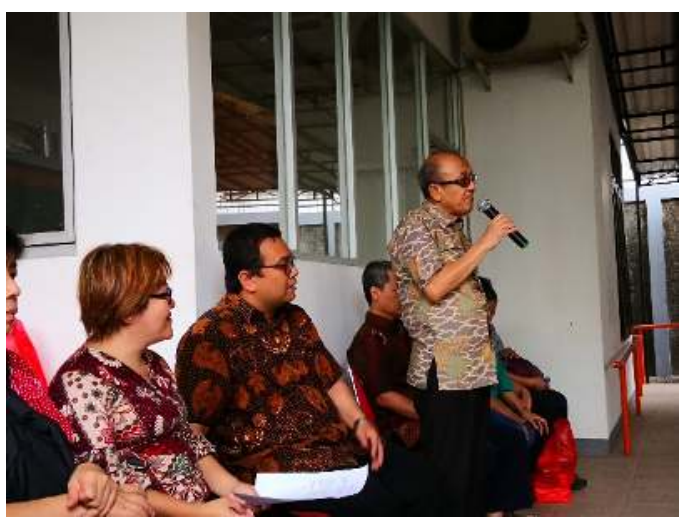

Gambar 8. Pembukaan acara oleh Bpk. Bambang

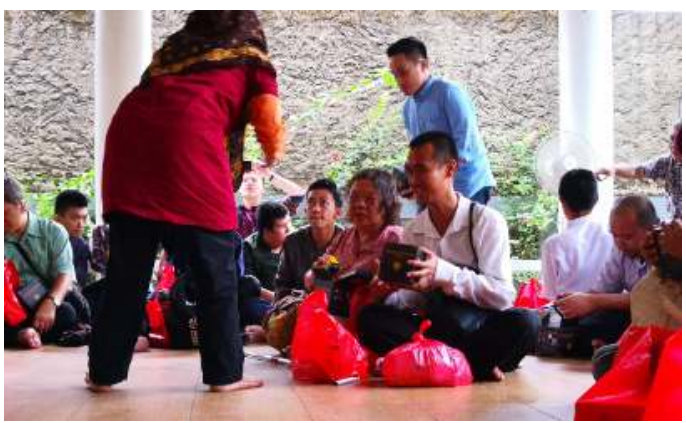

Gambar 9. Pemberian SonarVision

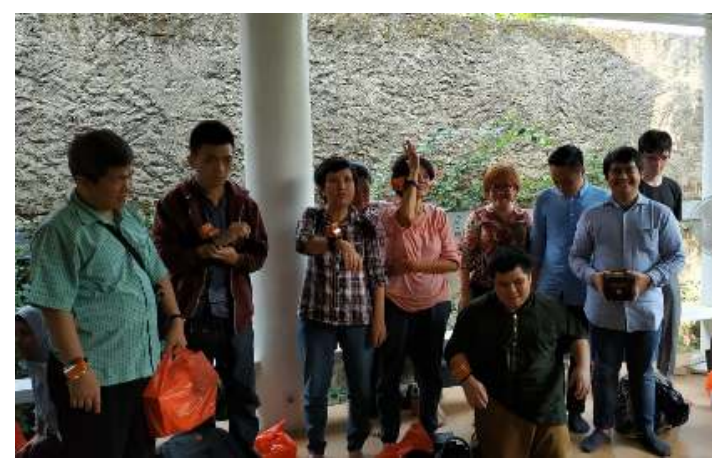

Gambar 10. Sosialisasi penggunaan Sonar Vision

Setelah melakukan sosialisasi dan pemberian alat Sonar Vision, kami melakukan survey secara acak kepada penerima Sonar Vision. Dari 50 orang yang kami survey $84 \%$ Orang menyatakan alat Sonar Vision lebih membantu apabila dibandingkan dengan tongkat. 100\% mengatakan sistem pengisian daya secara nirkabel membuat alat ini lebih praktis, 50\% menyatakan alat tidak perlu sampai menjadi 2 modul terpisah, mengenai pendapat mengenai kenyamanan pemakaian $76 \%$ menyatakan nyaman dengan alat ini.

\section{Simpulan}

Berdasarkan kegiatan pengabdian yang sudah dilakukan dalam program ini, maka dapat disimpulkan bahwa pembuatan, sosialisasi dan pemberian alat dalam upaya membantu penderita disabilitas tuna netra berjalan dengan baik. Implementasi terlaksana sesuai dengan rencana kerja dan capaian target. Pengguna puas terhadap kegiatan pengabdian yang sudah dilakukan.

Saran

Pengembangan alat Sonar Vision menjadi 1 modul sesuai saran dan penambahan fitur untuk melacak pengguna apabila alat dibawa keluar lingkungan rumah.

\section{Daftar Pustaka}

S. Alper, \& S. Raharinirina, "Assistive technology and mild disabilities," vol. 21, no. 2, pp. 4764, 1 March 2006.

D.H. Stefanov, Z. Bien, \& W.C. Bang, "The smart house for older persons and persons with physical disabilities: structure, technology arrangements, and perspectives," IEEE transactions on neural systems and rehabilitation engineering, vol. 12, no. 2, pp. 228-250, 2004.

E.E. Abdallah, \& E. Fayyoumi, "Assistive Technology for Deaf People Based on Android Platform," Procedia Computer Science, vol. 94, pp. 295-301, 2016.

P. Howe, "Cyborg and Supercrip: The Paralympics Technology and the (Dis)empowerment of Disabled Athletes," Sociology, vol. 45, no. 5, pp. 868-882, 2011.

F.D. Rose, B.M. Brooks, \& A.A. Rizzo, "Virtual reality in brain damage rehabilitation," Cyberpsychology \& behavior, vol. 8, no. 3, pp. 241-262, 22 June 2005.

E.F. Lopresti, A. Mihailidis, \& N. Kirsch, "Assistive technology for cognitive rehabilitation: State of the art," Neuropsychological rehabilitation, vol. 14, no. 1-2, pp. 5-39, 2004.

R Lederman, G Wadley, J Gleeson, S Bendall, \& M. Álvarez-Jiménez, "Moderated online social therapy: Designing and evaluating technology for mental health," ACM Transactions on Computer-Human Interaction (TOCHI), vol. 21 , no. 1, p. 5, February 2014.

J. Faria, S. Lopes, H. Fernandes, P. Martins, \& J. Barroso, "Electronic white cane for blind people navigation assistance," in 2010 
World Automation Congress, Kobe, Japan, 2010.

UltraCane, "Ultracane - the safer way to travel," Ultracane, 25 May 2018. [Online]. Available: https://www.ultracane.com/. [Accessed 29 July 2019].

U. Papa, \& G. Del Core, "Design of sonar sensor model for safe landing of an UAV," in 2015 IEEE Metrology for Aerospace (MetroAeroSpace), Benevento, Italy, 2015.

R. Abdubrani, \& S.S.N. Alhady, "Performance improvement of contactless distance sensors using neural network," in 11th WSEAS international conference on Instrumentation, Measurement, Circuits and Systems, \& 12th WSEAS international conference on Robotics, Control and Manufacturing Technology, \& 12th WSEAS international conference on Multimedia Systems \& Signal Proces, Rovaniemi, Finland, 2012. 